\title{
Numerical modelling of water percolation through mortar- based connection of concrete pipes
}

\author{
Marcin K. Widomski ${ }^{1, ~ *}$, Iwona Pawelec $^{2}$, Ajay Kumar ${ }^{3}$, and Grzegorz Lagód ${ }^{1}$ \\ ${ }^{1}$ Lublin University of Technology, Faculty of Environmental Engineering, Nadbystrzycka 40B, 20-618 Lublin, Poland \\ ${ }^{2}$ graduate, Lublin University of Technology, Faculty of Environmental Engineering, Nadbystrzycka 40B, 20-618 Lublin, Poland \\ ${ }^{3}$ National Institute of Technology, Department of Civil Engineering, 800005 Patna, India
}

\begin{abstract}
This paper presents an attempt to numerical modelling of water seepage through the connection of two concrete pipes, commonly used in the past in construction of sanitary and stormwater sewerage systems, sealed by three types of different cement-based mortars. The 2D numerical calculations were made by means of the commercial modelling software FEFLOW, WASY-DHI, especially popular in soil and environmental science. The required input data for the developed numerical model, including saturated hydraulic conductivity and retention characteristics of tested mortars, were obtained during the conducted laboratory measurements. The hydraulic characteristics of the applied concrete pipe were based on literature. The assumed boundary conditions reflected the concrete sewerage pipe filled by water to the height of $10 \mathrm{~cm}$ and the matric suction pressure of soil below the sand bed. Our numerical calculations showed diversified seepage intensity and accumulated volume of percolating water for the three tested mortars. The observed differences were in our opinion related to sand/cement ratio of each mortar. The higher sand content, the higher volume of seepage was noted.
\end{abstract}

\section{Introduction}

Ceramics, including concrete pipes, mortars and bricks, were in the past (until the end of the 20th century) one of the most popular materials used in construction of the sanitary and stormwater sewages systems in Poland. Concrete elements without sealing or sealed by various mortars, asphalt putty or tar ropes [1] were used to construct pipelines, manholes, chambers etc. Additionally, taking into consideration, the low quality of present materials, workmanship and available skills, the robustness of such sewage systems should be assessed as at least doubtful.

Migration of numerous different organic and inorganic pollutants contained in sanitary wastewater or storm water, including $\mathrm{BOD}_{5}, \mathrm{TSS}, \mathrm{TP}, \mathrm{NH}_{3}, \mathrm{Cd}, \mathrm{Cr}, \mathrm{Ni}$, $\mathrm{Hg}, \mathrm{Zn}$ etc. [2] to soil and groundwater through fractures of pipes, leaking connections as well as permeable, to some extent, sealing materials may pose a significant environmental threat to sustainable development of the area [3], limiting availability of clean water and arable soil $[4,5]$, so it should be prevented. Nowadays, application of up-to-date and modern piping and sealing materials, including plastics, polymer concrete, resins or rubber, allows to prevent or, at least, significantly minimise this threat. But the ceramic pipelines of dubious quality, with connections sealed by mortars, constructed several decades ago may still pose a significant threat due to drawbacks of construction, low quality of applied materials and erosion of concrete $[6,7]$.
Numerical modelling of water flow through porous media, extremely popular in soil and environmental science may be helpful in predicting the rate of water percolation through connection of two concrete pipes sealed by mortars. In our opinion FEFLOW, Wasy-DHI, Germany computational software $[8,9]$, may be useful in this case. This software was previously frequently applied in soil and environmental science to predict water flow and mass transport in saturated aquifers, as well as in variably saturated or unsaturated soil profiles $[10,11]$, including models of efficiency of compacted earthen sealing barriers for waste landfills, [12] and water outflow to soil environment during distribution pipes failures [13-15]. It was also successfully tested and verified in studies of water flow in porous building material during modelling of capillary rise in the block of aerated concrete [16].

This paper presents the attempt to two-dimensional numerical prediction of seepage of water through connection of the segments of concrete pipe variable sealed by three mortars of different cement vs. sand ratio.

\section{Materials and methods}

Presented numerical modelling of water percolation through connection of two concrete wastewater pipes, sealed by cement mortars of diverse composition was performed by the means of FEFLOW, Wasy-DHI, German computational commercial software. The

* Corresponding author: M.Widomski@ pollub.pl 
developed two-dimensional finite elements model consisted of 9813 elements and 5048 nodes, and reflected the studied cross section of two concrete pipes, connected one to another by mortar sealing of thickness equal to $1 \mathrm{~cm}$. The modelled pipes were placed on the compacted sand basis. The assumed time duration of simulation was equal to 365 days with the applied automatic control of time step length and iteration procedure error norm equalled 1.0E-03. The upper bound to time step length was determined as 0.01 day. The developed geometrical model with applied finite elements mesh is presented in Figure 1.

Three mortars of different composition were tested as joint sealing material:

- mortar A, Portland cement vs. sand volumetric fraction equal to $1: 2$;

- mortar B, Portland cement vs. sand volumetric fraction equal to $1: 3$;

- mortar C, Portland cement vs sand volumetric fraction equal to $1: 4$.

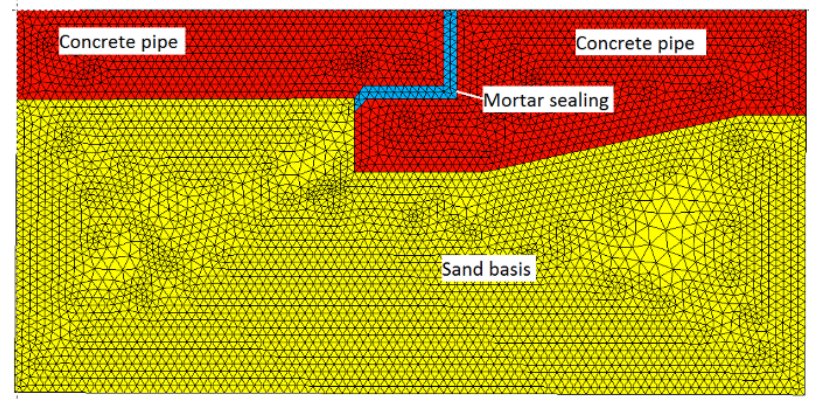

Fig. 1. Developed numerical model of two concrete pipes with connection sealed by mortar.

The software numerical calculations of the twodimensional water flow in porous media, including mortar, concrete and sand, of variable saturation, performed in the FEFLOW, were based on the standard forms of Darcy's and Richards' equations [17, 18]:

$$
\begin{gathered}
\boldsymbol{q}_{i}=-\boldsymbol{K}_{i j} \frac{\partial h}{\partial x_{j}} \\
\frac{\partial h}{\partial t}=-\frac{\partial \boldsymbol{q}_{i}}{\partial x_{i}} \mp Q
\end{gathered}
$$

where: $\boldsymbol{q}_{\mathrm{i}}-$ groundwater flux vector, $\mathrm{m} / \mathrm{s} ; h$ - water pore pressure head, m; $t$ - time, s; $\boldsymbol{K}_{\mathrm{ij}}$ - hydraulic conductivity tensor, $\mathrm{i}, \mathrm{j}=1,2, \mathrm{~m} / \mathrm{s} ; Q-$ sink or source term, $1 / \mathrm{s}$.

Input data, required to numerical modelling of water seepage through mortar sealing, including coefficient of saturated hydraulic conductivity and water retention characteristics, were based on laboratory measurements.

The values of coefficient of saturated hydraulic conductivity for the tested mortars were determined in $100 \mathrm{~cm}^{3}$ steel cylinders by the means of the falling head laboratory permeameters. The retention characteristics of the tested mortars were determined in the range of $0-15$ bar with application of the pressure extractors with ceramic plates by Soil Moisture, USA. The volumetric water content was obtained with the standard weight method according to ASTM C566-13 [19]. Figure 2 presents samples of tested mortars used to determine values of coefficient of saturated hydraulic conductivity and water retention characteristics.

The obtained results of measurements were fitted in Statistica 7.0 PL to the standard model of water retention curve introduced by van Genuchten [20] in the form based on the dimensionless degree of saturation:

$$
S_{a}=\frac{S_{S}-S_{r}}{\left[1+(A h)^{n}\right]^{m}}+S_{r}
$$

where: $S_{a}$ - actual degree of saturation; $S_{s}$ - saturated degree of saturation, assumed as $S_{s}=1 ; S_{r}$ - residual degree of saturation, $h$ - water pore pressure head, $\mathrm{m} ; A$ - fitting parameter, $1 / \mathrm{m} ; n, m$ - dimensionless fitting parameters: $m=1-n^{-1}$

The retention characteristics of modelled concrete and sand were assumed after literature [14,22]. The isotropic hydraulic characteristics of mortar, concrete and sand were established in the performed calculations due to the developed small-scale model [11]. Table 1 presents hydraulic characteristics of the applied porous materials assumed for modelling.
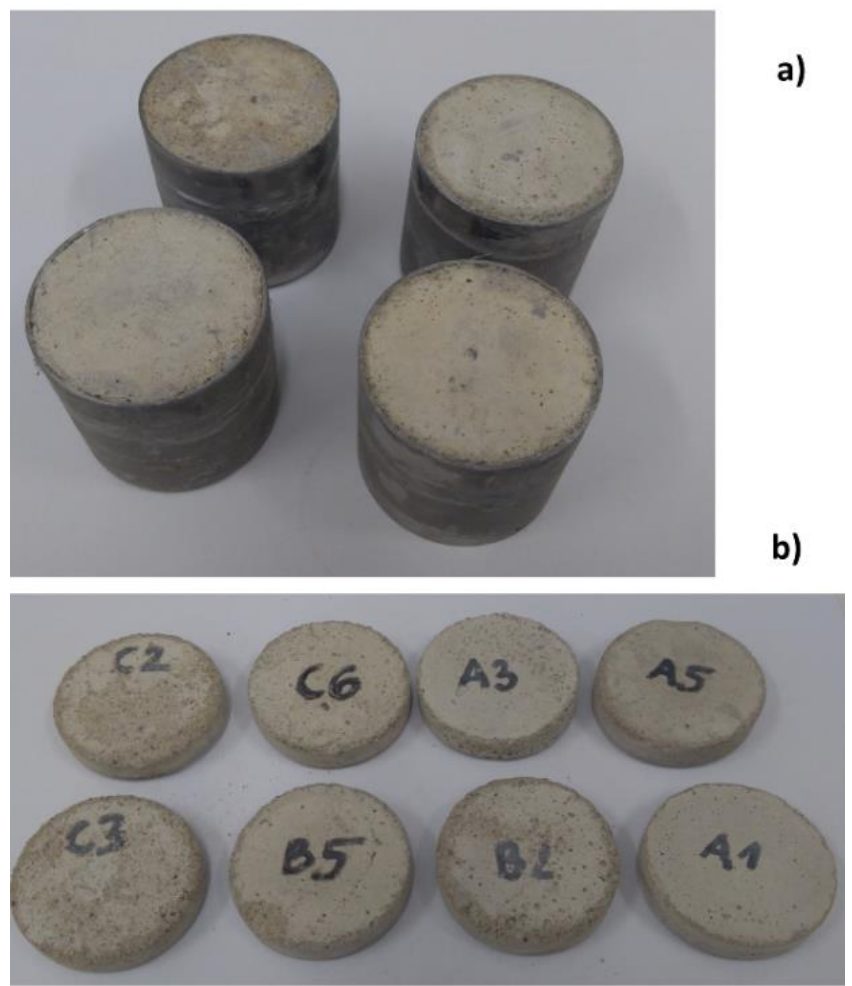

Fig. 2. Mortar samples used for determination of a) saturated hydraulic conductivity, in standard $100 \mathrm{~cm}^{3}$ cylinders, b) water retention characteristics.

The following boundary conditions were assumed to our numerical calculations: $0.1 \mathrm{~m}$ of pressure head as the top boundary condition, and $-1.0 \mathrm{~m}$ of pressure head as the bottom boundary condition at the boundary of sand basis. The applied initial conditions included degree of saturation 0.9 for sealing mortar and concrete pipe and 0.3 for compacted sand layer. 
Table 1. Hydraulic characteristics assumed to modelling.

\begin{tabular}{|c|c|c|c|c|c|}
\hline \multirow{2}{*}{ Material } & \multirow{2}{*}{$\mathrm{K}_{\mathrm{s}}$} & $\theta_{\mathrm{s}}$ & $\theta_{\mathrm{r}}$ & \multicolumn{2}{|c|}{$\begin{array}{c}\text { Water retention } \\
\text { curve fitting } \\
\text { parameters }\end{array}$} \\
\cline { 5 - 7 } & & & & $\mathrm{A}$ & $\mathrm{n}$ \\
\hline Mortar A & $1.65 \mathrm{e}-11$ & 0.220 & 0 & 0.149 & 1.019 \\
\hline Mortar B & $2.51 \mathrm{e}-11$ & 0.225 & 0 & 3.608 & 1.003 \\
\hline Mortar C & $3.12 \mathrm{e}-11$ & 0.225 & 0 & 0.0195 & 1.008 \\
\hline Concrete & $1.00 \mathrm{e}-12$ & 0.122 & 0 & 0.112 & 11.72 \\
\hline Sand & $2.00 \mathrm{e}-04$ & 0.370 & 0.11 & 2.30 & 7.70 \\
\hline
\end{tabular}

${ }^{*} \theta_{\mathrm{s}}{ }^{-}$saturated volumetric water content $\theta_{\mathrm{r}}{ }^{-}$residual volumetric water content

\section{Results}

Figure 3 presents distribution of water content in the modelled porous domain including the tested mortars, concrete pipes and sand basin, for two selected time steps. As it is visible in Figure 3, the process of water percolation through the studied mortars was very slow, the spatial distribution in all cases is nearly close. However, in case of Mortar $\mathrm{C}$, the greater range of increased water content may be observed.

In our opinion, behaviour visible in Figure 3 was quite predictable. After the initial period of lower saturation, the void space of mortar was filled with water to degree of nearly full saturation and allowed slow transport of water outside the pipe to sand of significantly lower saturation. This was, in our opinion, related to differences of saturated hydraulic conductivity presented by concrete and the tested mortars as well as different water retention characteristics. Figure 4 shows distribution of Darcy velocity at selected time step for all the tested mortars. Again, the clear relation between hydraulic parameters of the applied mortars and observed values, and distribution of the calculated flow velocity may be noted.

Figure 5 presents calculated annual accumulated volume of water seepage for $1 \mathrm{~m}$ of mortar sealing of width equal to $1 \mathrm{~cm}$, determined for the final cross section of the sealing. The greatest value of accumulated seepage was observed for Mortar C (6.48E-04 m³ while the lowest for Mortar A (3.04E-04 m³ $/ \mathrm{m})$. Thus, the close relation between volume of seepage and mortar composition was visible. The greater amount of sand fraction used to obtain the mortar, the greater calculated volume of seepage. The obtained volumes of percolating water may be assessed as small and negligible, but the whole length of pipelines and the number of pipe segments joints should be taken into consideration. Possibility of predicting the unit seepage volume for the selected ceramic sealing materials may be useful in cases of environmental and sustainability studies focused on availability and quality of water resources in urbanised basins, as well as anthropopressure exerted on the natural environment by wastewater and stormwater systems.
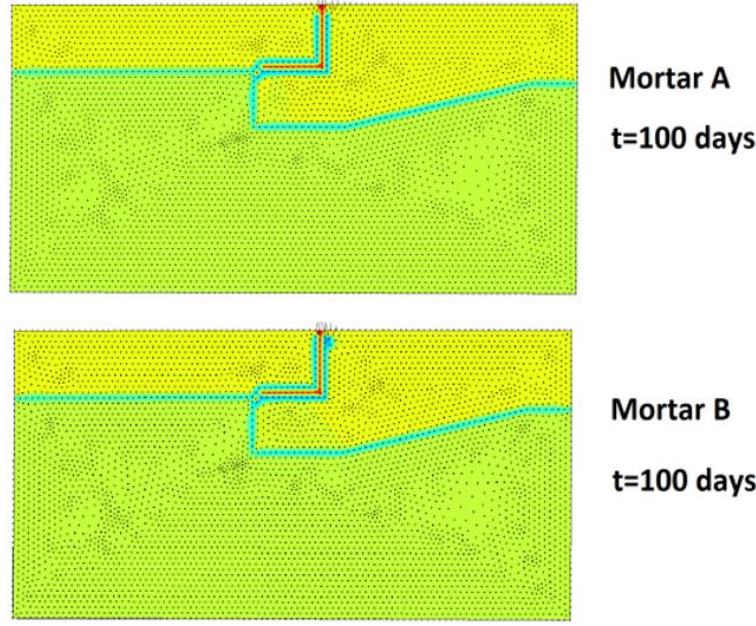

Mortar B

$\mathrm{t}=100$ days

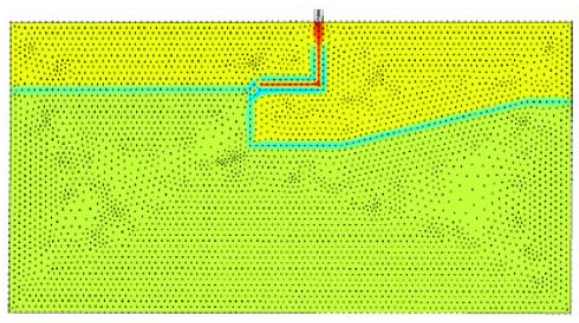

Mortar C

$t=100$ days

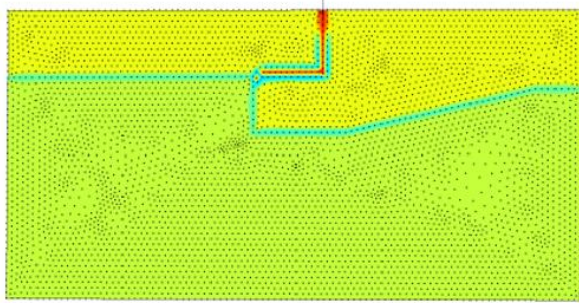

Mortar A

t-365 days

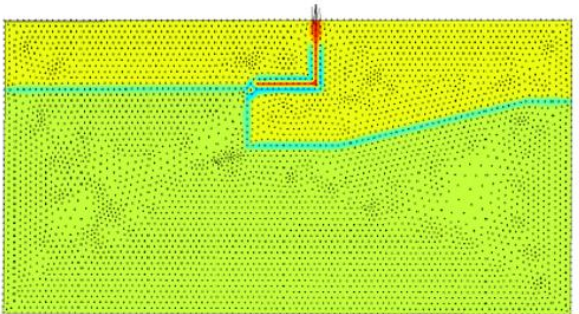

Mortar B

t-365 days

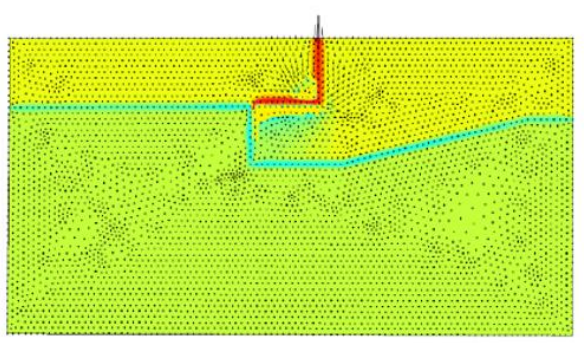

Mortar C

t-365 days

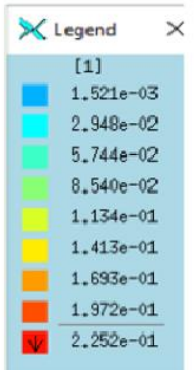

Fig. 3. Distributions of water content for all tested mortars and two selected time steps, $\mathrm{t}=100$ days and $\mathrm{t}=365$ days. 

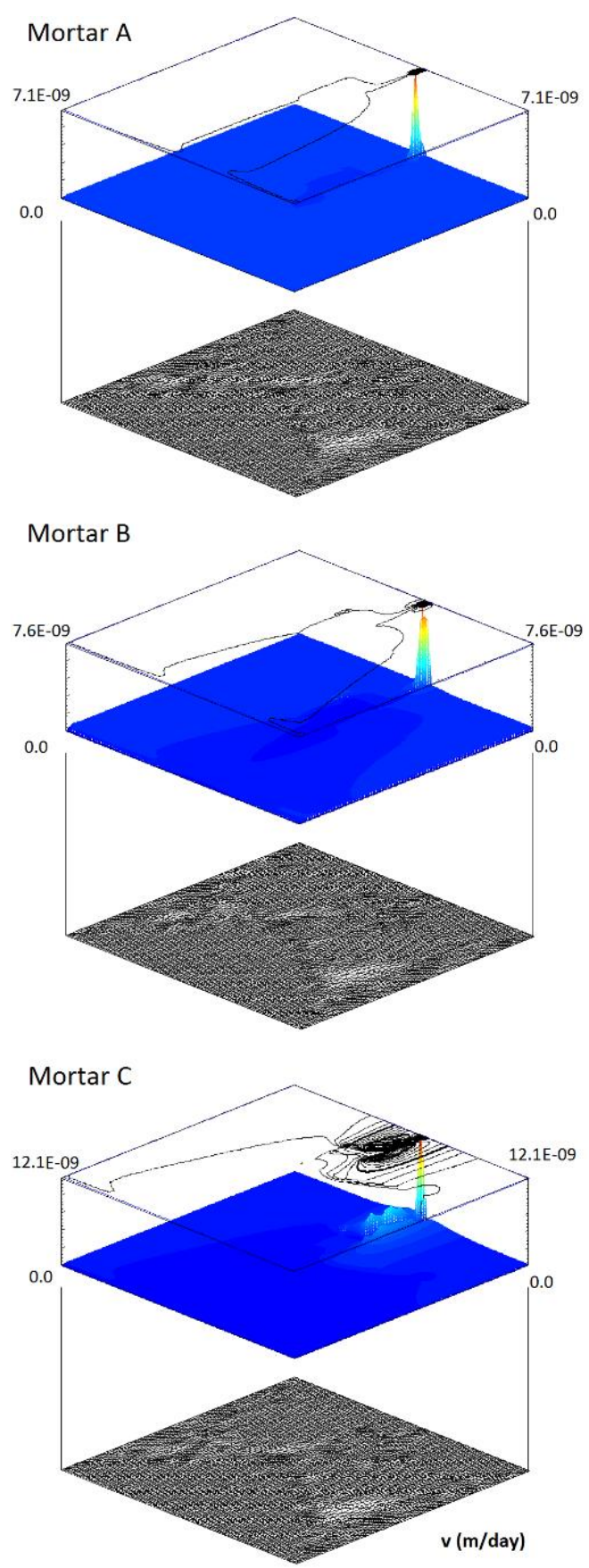

Fig. 4. Distribution of Darcy velocity (m/day) for selected, exemplary time step.

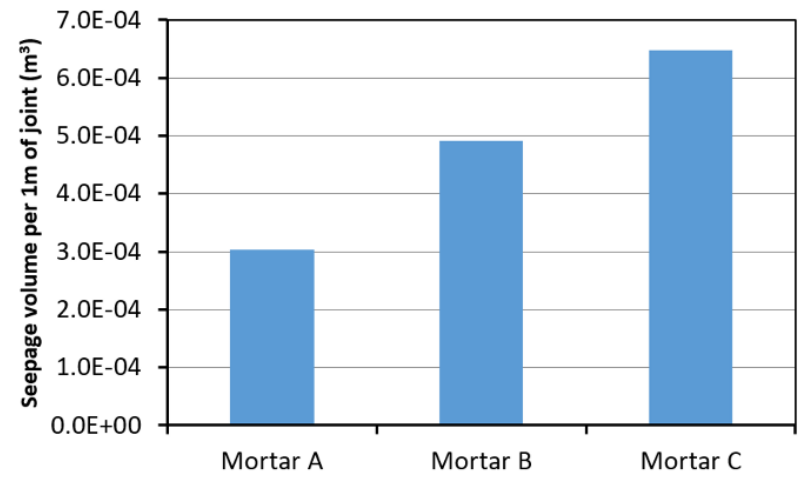

Fig. 5. Accumulated annual seepage volume for $1 \mathrm{~m}$ of pipe connection sealed by tested mortars.
In our opinion, the determined volume of annual seepage was strongly related to the coefficient of hydraulic conductivity, for saturated or close to saturated conditions, when gravity water was being kept inside the porous material by low values of matric suction pressure.

\section{Conclusions}

The performed numerical calculations of water percolation through connection of two concrete pipes sealed by mortars of various type allowed the following conclusions:

- The tested computational method commonly applied in soil science was capable to perform numerical calculations of water flow in ceramic building materials and allowed prediction wastewater seepage for three studied cement mortars of various composition.

- The required input data were measurable by the means of methods popular in soil science, including laboratory measurements of saturated hydraulic conductivity and determination of water retention curve.

- The determined annual accumulated volume of seepage was strongly related to saturated hydraulic conductivity of mortar, which in turn was dependant to the applied ratio of sand and Portland mortar.

- The highest annual unit volume of seepage equal to $6.48 \mathrm{E}-04 \mathrm{~m}^{3} / \mathrm{m}$ was noted for mortar containing $80 \%$ of sand, while the lowest, 3.04E-04 $\mathrm{m}^{3} / \mathrm{m}$, was determined for mortar in which Portland cement and sand were mixed in 1:2 ratio.

- In all cases, the determined value of annual seepage was at the similar range, below one cubic decimetre per year, thus, taking into consideration the possible length of pipelines in sewerage systems and number of joints, the resultant values of percolated wastewater may be significant.

- Presented method allowing prediction of sewage water percolation for ceramic sealing material, after determination of its basic physical and soil properties may be useful in environmental and sustainability studies for urbanised catchments.

- Our studies should be continued for different mortars, variable boundary conditions and with application of 3D model, also for pollutants mass transport.

\section{References}

1. C. Madryas, A. Kolonko, L. Wysocki, L. Konstrukcje przewodów kanalizacyjnych (Oficyna Wydawnicza Politechniki Wrocławskiej, Wrocław 2002)

2. P. Soonthornnonda, E.R. Christensen, Water. Res. 42, 1989-1998 (2008)

3. G.H. Huand, J. Xia, J. Environ. Manage. 61, 1-23 (2001)

4. U. Palme, M. Lundin, A.M. Tillman, S. Molander, Resour. Conserv. Recycl. 43, 3, 293-311 (2005)

5. I. Mariolakos, Desalination 213, 1-3, 147-151, (2007) 
6. L. Wysocki, Instal 4, 67-70 (2007)

7. M. Kwietniewski, J. Rak 2010, Niezawodność infrastruktury wodociagowej $i$ kanalizacyjnej $w$ Polsce (Komitet Inżynierii Lądowej i Wodnej PAN, Warszawa, 2010)

8. M.G. Trefry, C. Muffels, Ground Water 45, 525528 (2007)

9. H.J.G. Diersch, O. Kolditz, Adv. Water Resour. 25, 899-944 (2009)

10. M.K. Widomski, H. Sobczuk, W. Olszta, Soil Sci. Soc. Am. J. 74, 213-220 (2010)

11. M.K. Widomski, M. Iwanek, W. Stępniewski, Soil Sci. Soc. Am. J. 77, 8-18 (2013)

12. M.K. Widomski, S. Beck Broichsitter, A. Zink, H. Fleige, R. Horn, W. Stępniewski, J. Plant. Nutr. Soil Sci. 178, 401-412 (2015)

13. M. Iwanek, D. Kowalski, M. Kwietniewski, Ochrona Srodowiska 37(4), 13-17 (2015)

14. P. Suchorab, B. Kowalska, D. Kowalski, Rocz. Ochr. Sr. 18, 2, 416-427 (2016)
15. M. Iwanek, P. Suchorab, The assessment of water loss from a damaged distribution pipe using the FEFLOW software (ITM Web of Conferences, 15, 03006, 2017).

16. Z. Suchorab, M.K. Widomski, G. Łagód, H. Sobczuk, Proceedings of ECOpole 4, 2, 285-290 (2010)

17. P.A.C. Raats, Geoderma 100, 355-387 (2001)

18. H.J.G. Diersch, FEFLOW, finite element subsurface flow and transport simulation system reference manual (DHI-WASY Ltd., Berlin, 2009).

19. ASTM C566-13, Standard Test Method for Total Evaporable Moisture Content of Aggregate by Drying (ASTM International, West Conshohocken, 2013)

20. M.Th. van Genuchten, Soil Sci. Soc. Am. 44, 892-898 (1980).

21. V. Baroghel-Bouny, M. Mainguy, T. Lassabatere, O. Coussy, Cem. Conc. Res. 29, 1225-1238 (1999). 